\title{
Effect of storage on the brewing properties of tropical hop substitutes
}

\author{
Okoro, C.E. ${ }^{* *}$ \\ ${ }^{1}$ Dept of Food Technology, Yaba College Of Tech., Yaba-Lagos. \\ Aina J.O. ${ }^{2}$ \\ ${ }^{2}$ Dept. of Food Technology, University of Ibadan, Ibadan. \\ *Address for correspondence, E-mail:emoko102003@yahoo.com
}

\begin{abstract}
Tropical hop substitutes from Utazi (UTZ) Gongronema latifolium, Bitter Cola (BTC) Garcinia kola bitter leaf(BTL) Vernonia amygdalina and a blend (1:1.41:2.89) of the three (HSB) respectively, were produced. Stability studies were carried out to predict their suitability for brewing after one to six months storage at $5 \pm 1^{\circ} \mathrm{C}$ and $27 \pm 1^{\circ} \mathrm{C}$ respectively. These were determined using the level of reduction in their á-acid, iso-á-acid, soft resin, analytical bitterness and degree of utilization levels. Result showed that there was a general reduction of between $10 \%$ to $30 \%$ in these parameters. However, the (HSB) recorded lower losses than BTC, BLF, and UTZ. Also the samples were more stable at
\end{abstract}

ABSTRACT

$5 \pm 1^{\circ} \mathrm{C}$ than at $27 \pm 1^{\circ} \mathrm{C}$. Samples treated with $\mathrm{Ca}(0 \mathrm{H})_{2}$ had lower rate of decrease in stability with percentage loses of between $5 \%$ to $15 \%$ recorded in all the samples. Pertinently, these levels of reduction were comparable to the level of losses reported in conventional temperate hops (Humulus lupulus) stored under similar conditions. Therefore, the tropical hop substitutes when stored at $5 \pm 1^{\circ} \mathrm{C}$ to $27 \pm 1^{\circ} \mathrm{C}$ still retained an acceptably high level of their hops properties that is adequate for beer brewing.

Key words: Hop substitutes, hops, á-acid, iso-á-acid analytical bitterness, brewing.

\section{INTRODUCTION}

$\mathrm{H}$ Tops are produced from the flowers of the plant, Humulus lupulus, and is a major raw material used in beer brewing for imparting flavour, colour, bitterness, foam head stability and antiseptic properties, (Hough 1986). However, hop plant is a temperate crop and has not been successfully grown in tropical countries like Nigeria, hence its importation for beer brewing is imperative. According to the Federal Office of Statistics (1986) report, it cost Nigeria about 5.5 million dollars to import hops in 1985. This high cost trend could be reduced if hops substitutes can be sourced locally.

Since the Hops of commerce is bitter, some edible tropical vegetables with bettering principles have been researched into as potential hops substitutes. Gentalium (1985) reported the use of bitter leaf, (Gongronema latifolium) in brewing the popular Tela-beer in Ethiopia. Okafor and Anichie (1983) brewed an acceptable lager beer with Utazi leaf (Vernonia amygdalina). Bitter cola (Garcinia kola), according to Hutchinson and Dalziel(1985), enhances flavour of local drinks when chewed while drinking them.

Okoro, (1990) and Okoro (1993) developed a tropical hops substitute blend from Utazi, bitter cola and bitter leaf combined in the ratio of 1: 1.41: 2:89 respectively. The lager beer produced using this tropical hop substitute blend (HS-Blend) was reported to be comparable and significantly not different from beers brewed with the conventional temperate hops.

The use of these tropical hop substitutes were due to their high content of alpha-acids, iso-alpha- 
acid and essential oils at levels comparable to those of the temperate hop substitutes, (Okafor and Anichie, 1983; Okoro, 1993). However, no storage stability studies have been conducted on these hop substitutes developed from tropical plants.

This is necessary because the alpha-acids, isoalpha-acids and essential oils found in these tropical hop substitutes may be unstable with storage.

The aim of this work is therefore to determine the level of retention of bitterness and flavour principles in these tropical hop substitutes at different storage conditions and duration. To determine the influence of different preparations or treatments on the shelf life of these hop substitutes.

\section{MATERIALS AND METHODS Raw Materials Procurement}

The Bitter leaf, Bitter cola and Utazi were procured fresh from Mile 12 market, Lagos. They were washed, destalked or decorticated (for bitter cola) sorted and dried at $50 \pm 2^{\circ} \mathrm{C}$ to moisture content of $10 \pm 2 \%$ in drought air oven. After which they were milled into powder, using hammer mill (chrysty - lab mill model 8) to $0.1 \mathrm{~m}$ diameter particle size. The powders were blended in the ratio of 1: 1.41: 2.89, utazi: bitter cola: bitter leaf respectively, as established using linear programming (Okoro, 1990; 1993). The blend was compounded into $1 \mathrm{gm}$ pellets using a laboratory hand screw press locally designed and fabricated.

\section{Shelf-stability studies}

Reports on the trial brewing with these samples were reported by Okoro, 1993. The four hop substitutes were utazi Pellet (UTZ). Bitter LeafPellet (BLT) Bitter Cola Pellet (BTC) and Hop substitutes Blend (HSB). To further improve the stability before storage, another set of the HSB was blended with $1 \% \mathrm{Ca}(\mathrm{OH})_{2}$ before palletizing it.

All the samples were vacuum packed respectively in high density polyethylene bags and stored at $27 \pm 1^{\circ} \mathrm{C}$ and $5 \pm 1^{\circ} \mathrm{C}$ for period ranging from 1 to $6 \mathrm{mth}$. The stability and quality changes of the samples over this storage period were monitored every two months by determining their levels of soft resin retention, á-acid retention, iso-á-acid retention, bitterness level retention and the, Degree of Hop utilization.

\section{Soft resin determination}

Ten grammes of each sample was dissolved in $10 \mathrm{ml}$ of hexane, thoroughly stirred and filtered (using watman No 14 filter paper). Filtrate was dried to a constant weight at $50^{\circ} \mathrm{C}$. The soft resin was calculated as the percentage of the original weight of sample dissolved in the hexane.

\section{A-acid determination}

To an $0.15 \mathrm{gm}$ of the samples was added $100 \mathrm{ml}$ cold methanol in a Gallenkamp shaker flask shaker. The solution was then centrifuged at $2500=\mathrm{rpm}$ for $20 \mathrm{~min}$ and the decanted supernatant was acidified with $0.002 \mathrm{~N} \mathrm{HCl}$ and its absorbance at $355 \mathrm{~nm}$, $325 \mathrm{~nm}$ and $275 \mathrm{~nm}$ was determined using spectro photometer (Pye-unicam SP6-550 UV/VIS. Model) and the alpha acid calculated using AOAC (2000) methods: alpha acid $(\mathrm{mg} / \mathrm{L})=73.79(\mathrm{~A} 325)-51.56$ (A355) - 19.07 (A275) where $\mathrm{A}$ is absorbance reading at the specified wave length.

\section{Iso-alpha-acid determination:}

$15 \mathrm{ml}$ sample extract was acidified with $0.5 \mathrm{ml}$ $6 \mathrm{~N} \mathrm{HCl}$ and mixed with $15 \mathrm{ml}$ of pure iso-octane in a shaker (Gallenkamp flask shaker), $10 \mathrm{ml}$ of the isoactane extract was washed with $10 \mathrm{ml}$ of a mixture of methanol and $4 \mathrm{~N} \mathrm{HCl}(68: 32 \mathrm{v} / \mathrm{v})$. After which $5 \mathrm{ml}$, of the washed iso-octane layer was diluted with $5 \mathrm{ml}$ of alkaline methanol $(60: 40 \mathrm{v} / \mathrm{v}$ methanol: $0.5 \mathrm{~N}$ $\mathrm{NaOH}$ ) and its absorbance read at $255 \mathrm{~nm}$. The isoá-acid (mg/L) was calculated according to AOAC (2000) method.

Iso-alpha acid $(\mathrm{mg} / \mathrm{L})=\mathrm{A}_{255}(96.15)+0.4$

\section{Analytical bitterness determination}

An $0.15 \%(\mathrm{w} / \mathrm{v})$ solution of the respective samples were made using distilled water. The solution was boiled for 90min cooled and filtered using watman No 14 filter paper. $10 \mathrm{ml}$ of the water extract of each sample were acidified with $0.5 \mathrm{ml} 6 \mathrm{~N} \mathrm{Hcl}$ 
and subsequently extracted with $20 \mathrm{ml}$ of iso-octone in a shaker (Gallenkamp Flask Shaker). The absorbance of the iso-octane extract was determined at $275 \mathrm{~nm}$ using a spectrophoto meter (Pye-unicam SP 6-550 UV/VIS model). The analytical bitterness was calculated according to EBC (1989) method and reported as Analytical Bitterness unit ( $\left.{ }^{0} \mathrm{EBU}\right)$.

\section{RESULTSAND DISCUSSION}

Results in Table 1 show that the soft resin content of all the tropical hop substitutes (THS) decreased with storage, with HSB reducing by (1015\%), UTZ (15-30\%) BLF (12-19\%) and BTC (10-23\%) over 6 months storage. These results compares well with losses in resins reported for the conventional hops stored at $25^{\circ} \mathrm{C}$ for 30 weeks (12$17 \%)$ by Marr (1985) and Laws (1984). The reduction in the soft resin content of hops is a common phenomenon which is associated with the oxidations depreciation of the soft resins to hard resins with storage hough (1986). However, the low percentage reduction especially, with storage at $5^{\circ} \mathrm{C}$ show that the THS can still retain up to $70-85 \%$ of their bitterness properties hence could still function well as hop substitute for brewing after 6 months of storage.

The stability of the á-acid component of the soft resin of any given hop is very important in determining the suitability of the hop for brewing. It is the á-acid that impacts the bitterness in the beer. Results in Table 2 show that the alpha-acid content of the tropical hop substitutes (THS) were more stable at $5 \pm 1^{\circ} \mathrm{C}$ than at $27 \pm 1^{\circ} \mathrm{C}$ storage with reduction of $(15.0 \%)$ for HSB, (21\%) for UTZ, (15.41\%) for BLF and 31\% for BTC. However, the a-acid content of the hop substitutes blend was more stable than those present in the individual substitutes. Generally, the low stability of the a-acid is associated with that of the soft resins. This, according to Hough (1986) is due to oxidation of a-acid with storage.
$\mathrm{A} 275={ }^{\circ} \mathrm{EBU}$, were Ain absorbance at $275 \mathrm{~nm}$.

Degree of utilization determination: The degree of utilization of the Bittening potentials in the hop substitute were calculated as:

$\%$ utilization $=\frac{\mathrm{mg} / \mathrm{l} \text { iso-alpha-acid } \times 100}{\mathrm{mg} / \mathrm{l} \text { alpha-acid }}$

The Bitterness levels of the hop substitutes samples (Table 3) reduced, with storage at both storage temperatures. However, the percentage reductions in bitterness units were observed to be lower (between $0.5 \%$ to $8 \%$ ) than percentage losses in á-acid of the samples. This is consistent with the report of Gill et al. (1979) that the loss in bitterness potentials of stored hops was usually less that $50 \%$ of the reduction in its á-acid and soft resin values. This according to Hough (1986) is because some oxidation products of á-acid and B-acids are themselves bitter and that contributes to the bitterness values of hops.

The reduction in the percentage utilization of the bitterness principles in the hop substitutes with storage (Table 4), were also not as high as recorded for á-acid reduction with storage (Table 2). A net reduction in utilization of $14.89 \%$ for $\mathrm{HSB}, 11.05 \%$ UTZ, $14.30 \%$ BLF and $11.09 \%$ for BTC were observed. This is because the percentage utilization, like the bitterness level (table IV) are not only caused by the á-acid level but also by its iso- á-acid level. According to Hough 1986, the percentage utilization is measure of the extent of extraction of á-acids and its isomerization and bitterness potentials in water, wort or beer. The utilization level obtained from the HSB (34\%) BTL (32\%), BTC (30\%) and UTZ (28\%) after 6 month of storage, compares well with those reported by Laws (1983) for the conventional hops (34-37\%). 
There was a marked increase in the á-acid stability of tropical hop substitutes treated with $\mathrm{Ca}(\mathrm{OH})_{2}$ before palletizing and those not treated (table V). HSB treated with $\mathrm{Ca}(\mathrm{OH})_{2}$ and stored for six-months at $27 \pm 1^{\circ} \mathrm{C}$ had a $12.81 \%$ reduction in á-acid level compared to the untreated HSB with $20.54 \%$ reduction in á-acid values. The same trend was observed in UTZ (26.51\%: $31.65 \%)$ BLF (14.11: 21.20) BTC (21.25: 28.50) respectively.
This is consistent with the use of $\mathrm{Ca}(\mathrm{OH})_{2}$ as hop stabilizer in the conventional hop pellet production. The observed improvement in the stability of á-acids in $\mathrm{Ca}(\mathrm{OH})_{2}$ treated pellets may be due to the formation of calcium salts of the á-acid. The Ca- áacid salts, according to Grant (1979) are more stable to oxidation than á-acid.

Expectedly, all samples stored at $5 \pm 1^{\circ} \mathrm{C}$ recorded more stability in all parameters than those stored at $27 \pm 1^{\circ} \mathrm{C}$ this is consistent with the stabilization effect of cold temperature storage against oxidation changes. 


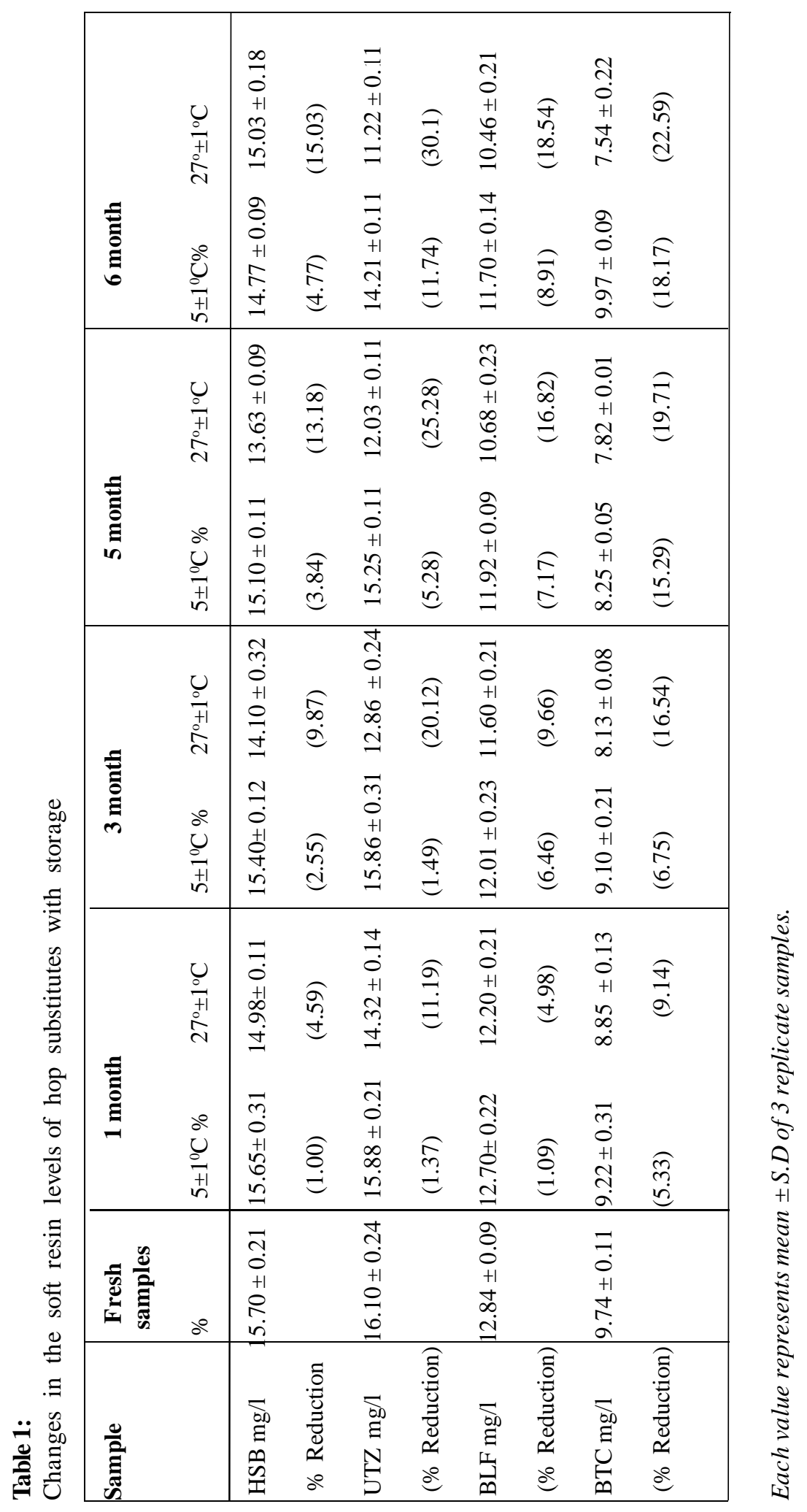




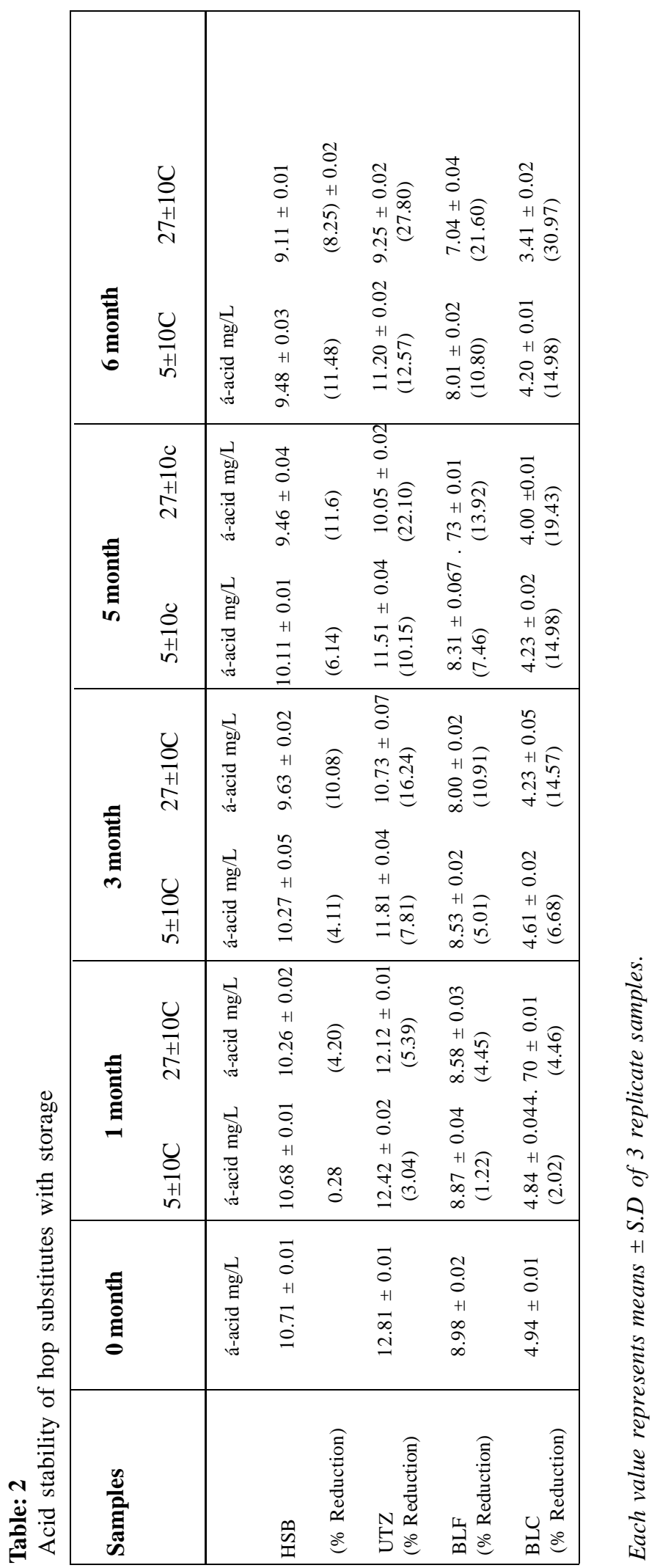




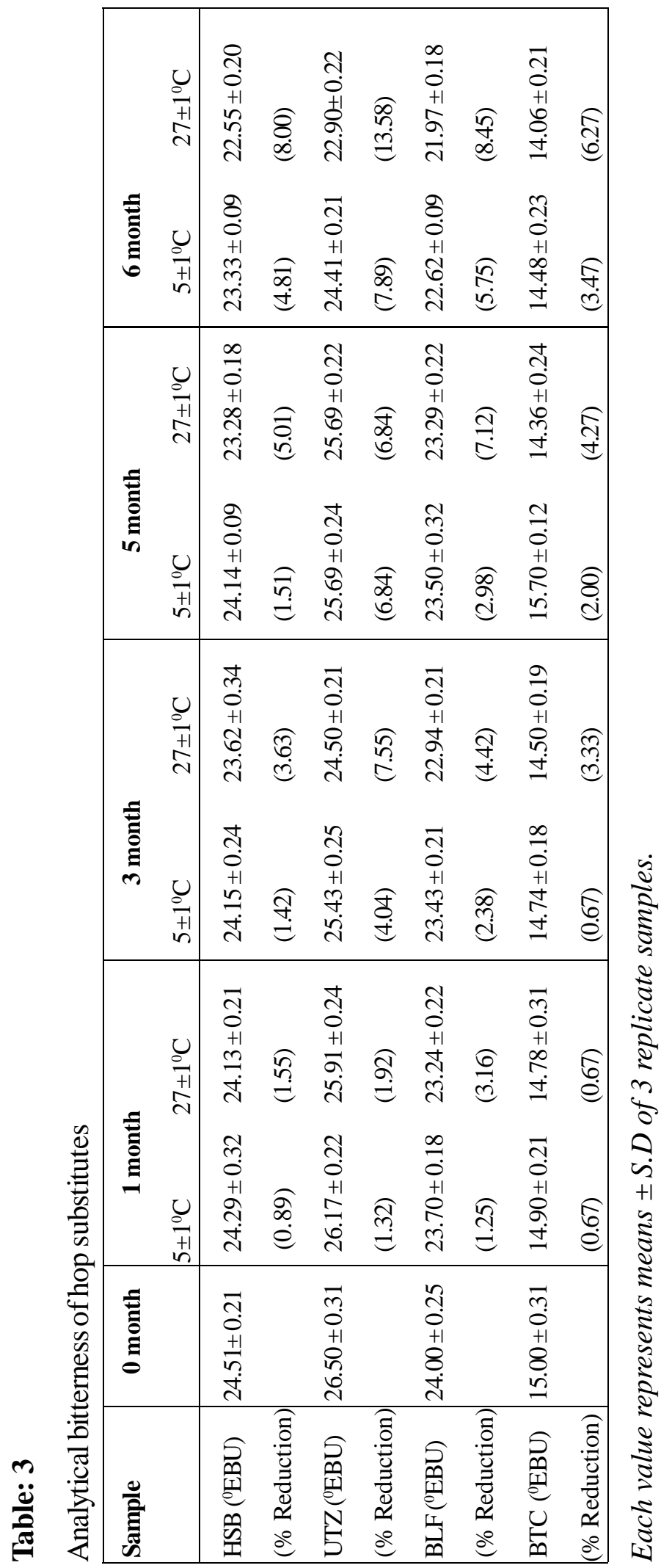




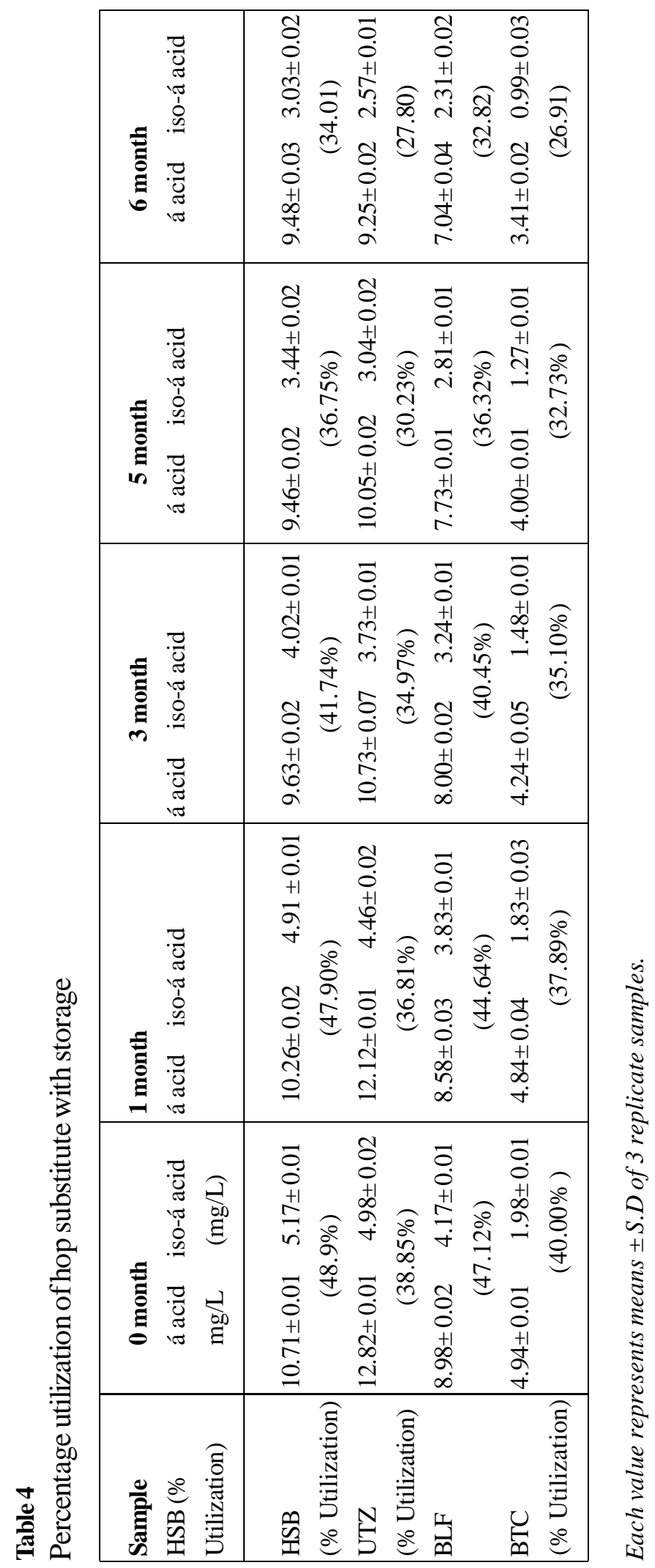




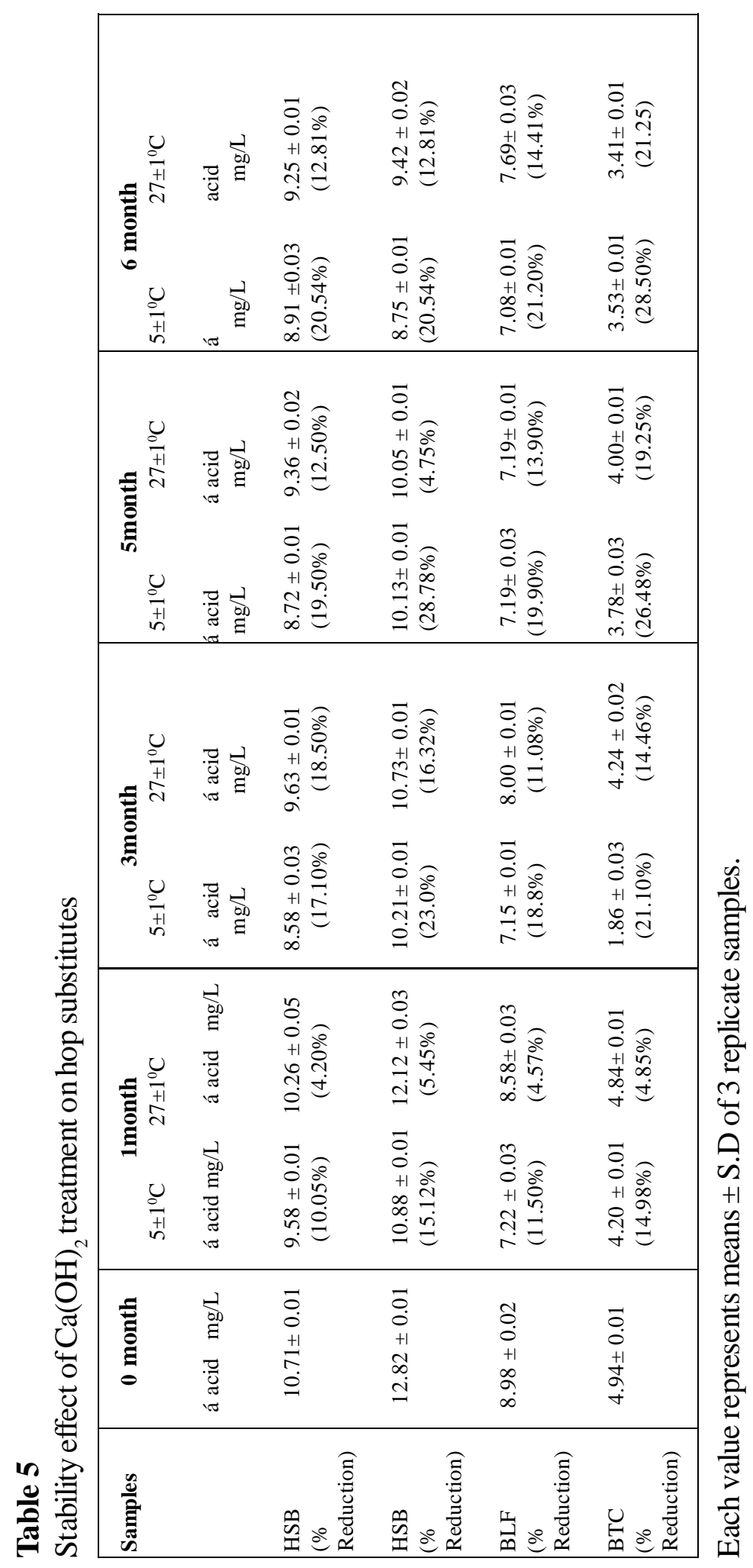




\section{CONCLUSION}

The observed reduction in the soft resin levels áacid levels. bitterness levels and utilization levels with storage of the tropical hop substitutes are consistent with storage changes, but their levels of reduction are similar to those recorded for the stored conventional hops especially, if treated with $\mathrm{Ca}(\mathrm{OH})_{2}$ before palletizing and storing at $5 \pm 1^{\circ} \mathrm{C}$. Essentially, tropical hop substitutes, if produced and utilized within three to six-month can yield sufficient bitterness principles when used in beer brewing. To obtain a shelf stable hop substitute from the tropics a blend of the three identified substitutes (UTZ, BFL and BTC) treated with $1 \% \mathrm{CA}(\mathrm{OH})_{2}$, palletized, vacuum packed and stored at $5 \pm 11^{\circ} \mathrm{C}$ and used within 6 months of storage is recommended.

\section{REFERENCES}

AmericanSociety of Brewing Chemist (1993). Methods of Analysis. $10^{\text {th }}$ edition. Washington D.C. p 560-562.

AOAC (2000) Official Methods of Analysis, $17^{\text {th }}$ Edition Vol II, Chapter 27, p16.

European Brewing Convention. Analytical EBC (1989) Issued by the Analysis Committee of the European Convention. $8^{\text {th }}$ edition. London.

Federal Office of Statistics (1986). The Nigerian trade summary. Federal Ministry of Commerce and Industry Abuja, Nigeria.

Gentalium, A. (1985) some common medicinal and poisonous plants used in Ethiopian folk medicine in: Useful plants of West Tropical Africa. Vol. 1, $2^{\text {nd }}$ edition (edited by Hutchinson, K.J and Dalziel, M.J) Royal Botanical gardens, Kew, London p 503-508.
Gill, R., Laws, D.R.J., Goldfinch, P. and Henley H.P. (1979). Storage characteristics of some hop varieties. Journal of the Institute of Brewing 85(2); p 243-247.

Grant, H.L. (1978) Developments in the science of Hops. Master Brewers Association of the Americans 15(14); p 224-228.

Hough, J.S. (1986) Hops and Wort Treatment in: Introduction to Brewing Science and Technology Part 1 (eds Rainbow, C. and Fleat, G.E.S) $6^{\text {th }}$ edition. The Institute of Brewing London, p 28-41.

Hutchinson,K.J. and Dalziel, M.J. (1985) The useful plants of West Tropical Africa vol. 1, $2^{\text {nd }}$ edition. Royal Botanic Gardens, Kew, London, p 501-508.

Laws, D.R.J. (1983) Commercial Brewing and Storage Trials with Yeamen Hop. Journal of the Institute of Brewing 89(2); p 92-95.

Marr J.F. (1985) Hop Industry Committee Analysis of Hop of 1984 crop: Areport Journal of Institute of Brewing 91(1); p 184-191.

Okafor, N. and Anichie, G.N. (1983) West African Hop Substitutes for Sorghum Lager Beer. Brewing and Distilling International 13(1); p 20-31.

Okoro, C.C. (1990) Development of Tropical Hops substitute for the Nigerian Brewing Industry. MSc Thesis, submitted at University of Ibadan, Nigeria.

Okoro C.E. (1993) Development Hop substitutes from Tropical Plants. NBTE Journal of Agricultural Technology Maiden edition, p 30-35. 